\title{
A Hybrid Closed-loop Insulin Delivery System for the Treatment of Type I Diabetes
}

\author{
E Finny Moses
}

\begin{abstract}
The hybrid closed-loop insulin delivery system serves as the world's first synthetic (artificial) pancreas. The hybrid closed-loop insulin delivery system will help the type I diabetes patients in controlling their insulin quantity in the body. This was approved in late 2017 by the Food and Drug Administration (FDA), which owns a neotechnology that enables to have a direct link between the device and insulin pump to even out blood glucose at an exceptional level. This technology switches the "open loop" system that needs patients to access their own information to calculate how much insulin has to be injected. Many type I diabetes mellitus (DM) patients demand this technology in 2019. Many experts also predict that a similar technology will hit community soon for the type II diabetes patients.
\end{abstract}

Keywords: Al in blood sugar control, Artificial pancreas, Continuous glucose monitor, Hybrid closed-loop insulin, Synthetic pancreas.

Pondicherry Journal of Nursing (2019): 10.5005/jp-journals-10084-12104

\section{INTRODUCTION}

In the people who suffer with type I diabetes, either the pancreas do not release any insulin or it does not produce adequate insulin. These people will have to inject insulin every day in order to control the blood sugar level within the normal range. In order to perform this procedure, the patient must check their blood glucose level frequently by fingerstick method or by using a continuous glucose monitor and then the exact dose of insulin is calculated to be injected. On contrary, injecting too much insulin into the body will lead to hypoglycemia, which is a great risk when it occurs during sleep at night. ${ }^{1}$ Also taking reduced dose of insulin will lead to hyperglycemia, or high blood sugar where diabetic ketoacidosis which builds a chemical called as the ketones, which are produced when the body fats are used to produce energy instead of using glucose. ${ }^{3}$ When these conditions swings high and low at unpredicted times of life, they are highly associated with amplified mortality and morbidity. ${ }^{1,2}$

Some wearable devices are available for the constant control of type I diabetes. But these systems are planned to manage blood sugar through particularly risky times, such as, at meal times, overnight and when doing exercise (Fig. 1). ${ }^{3}$

Three functions combine the wearable systems while delivering insulin:

- Continuous blood glucose monitoring

- Insulin delivery through a pump

- Use of specific algorithms in control of insulin., ${ }^{4,5}$

The constant glucose monitor sends values of glucose to the specific algorithms in the insulin pump, and the algorithm determines the insulin required based on the sensor calculation and the quantity of lively insulin present already in the individual. ${ }^{4,5}$ By incorporating these three functions, it automatically creates a close loop system any involvement of the patient. ${ }^{5}$ In contrast, a hybrid closed-loop system will still requires a user interventions. ${ }^{6}$

\section{The Technology}

By a small incision the guardian sensor is implanted under the skin and secured with a tape for a single use that can be set for a period
Department of Medical Surgical Nursing, Kasturba Gandhi Nursing College, Sri Balaji Vidyapeeth, Puducherry, India

Corresponding Author: E Finny Moses, Department of Medical Surgical Nursing, Kasturba Gandhi Nursing College, Sri Balaji Vidyapeeth, Puducherry, India, Phone: +91 9597341627, e-mail: finnymoses07@ gmail.com

How to cite this article: Moses EF. A Hybrid Closed-loop Insulin Delivery System for the Treatment of Type I Diabetes. Pon J Nurs 2019;12(1):25-27. Source of support: Nil

Conflict of interest: None

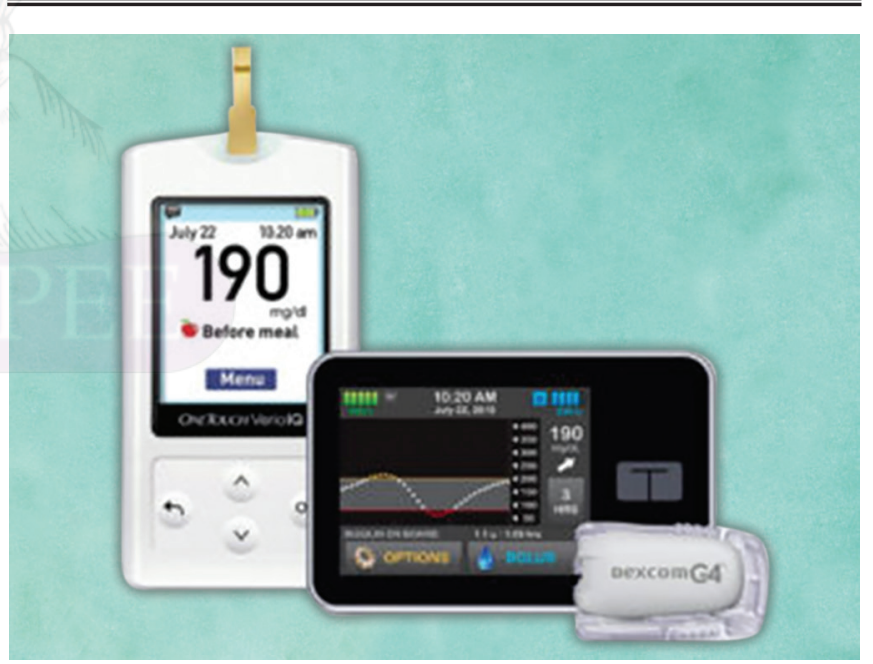

Fig. 1: Hybrid closed-loop insulin delivery system—the device itself

of seven days. The technology works by measuring the glucose levels which is presented surrounding the device and cells below the skin (interstitial fluid). The fingerstick tests is not replaced by the sensor to conclude the required insulin for food and activities. ${ }^{6,7}$ And for everyday monitoring it requires a minimum of two finger-stick calibrations. ${ }^{6}$ The value of blood sugar is automatically transmitted to the insulin pump. A water proof insulin pump, which runs on battery power, has the capacity of programming the rate by itself

(-) The Author(s). 2019 Open Access This article is distributed under the terms of the Creative Commons Attribution 4.0 International License (https://creativecommons. org/licenses/by-nc/4.0/), which permits unrestricted use, distribution, and non-commercial reproduction in any medium, provided you give appropriate credit to the original author(s) and the source, provide a link to the Creative Commons license, and indicate if changes were made. The Creative Commons Public Domain Dedication waiver (http://creativecommons.org/publicdomain/zero/1.0/) applies to the data made available in this article, unless otherwise stated. 


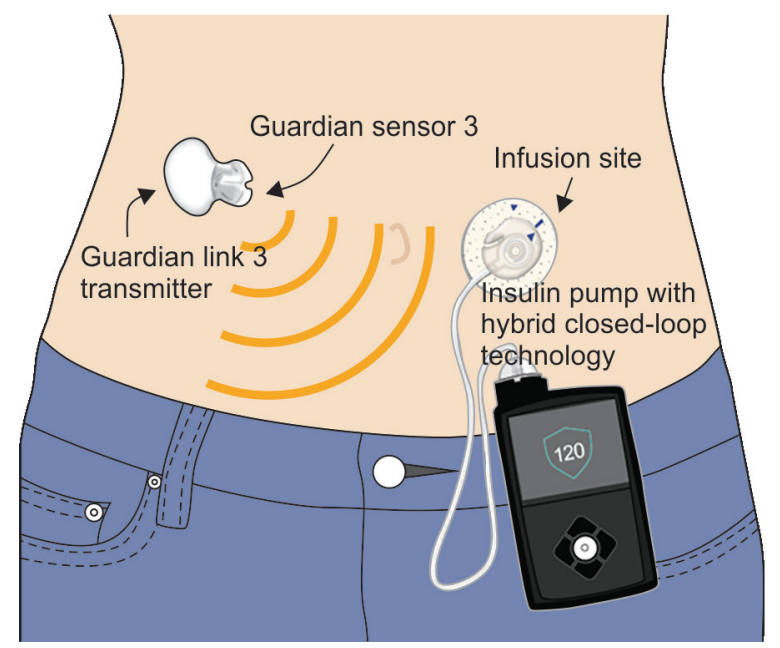

Fig. 2: The mechanism behind hybrid closed-loop insulin delivery system

by calculating the patient's blood sugar value. ${ }^{8,9}$ Then a reservoir which stores insulin will get activated and a required dose of insulin is released through the microinfusion pump in to the patient's blood stream. ${ }^{8}$

The guardian link transmitter, which is directly connected to the glucose sensor, will collect the values of blood glucose and the administered insulin rate that can be stored in sensor data and can be reviewed up to 90 days (Fig. 2). ${ }^{3}$

Both automatic or manual mode is supported by this system, but in both of this mode, the user has to enter manually the approximated value of carbohydrates which will be consumed at meals and simultaneously agree the insulin bolus which is suggested by the system. ${ }^{3}$

The system follows an algorithm to automatically regulate the basal insulin levels in an automatic mode (the insulin that keeps the blood sugar stable between meals or during sleep). ${ }^{10}$

As for the manual mode, the patient can mark the pump to postpone activity at or before low glucose values. The insulin release will automatically hang up activity when the glucose level lowers or is predicted to go down to a preferred threshold. ${ }^{10,11}$ Also this values can be remotely transmitted from the system and can be monitoring through a telemedicine which is very much possible. ${ }^{12}$

\section{Who Might Benefit?}

At present, they are much proposed by people who are older than 14 years of age and who suffers type I diabetes who requires at least 8 international units of insulin every day. ${ }^{13}$ Also patients with noteworthy nocturnal hypoglycemia, or hypoglycemia who are unaware, could be particularly benefited from this technology. ${ }^{14}$ Since this system needs fingerstick tests for calibration, before meals and exercises, it is not appropriate for the unwilling patients or for the patients who are unable to do a frequent fingerstick glucose measurements. ${ }^{13,15}$

\section{Minor Issues}

In spite of the interest of DM patients and physicians, the experts have renowned that the former advance like the constant glucose monitoring, has not yet granted for a standard diabetes therapies for the following reasons:

- Quick changes, such as having rapid meals and fast exercise can make constant blood glucose monitoring less accurate than

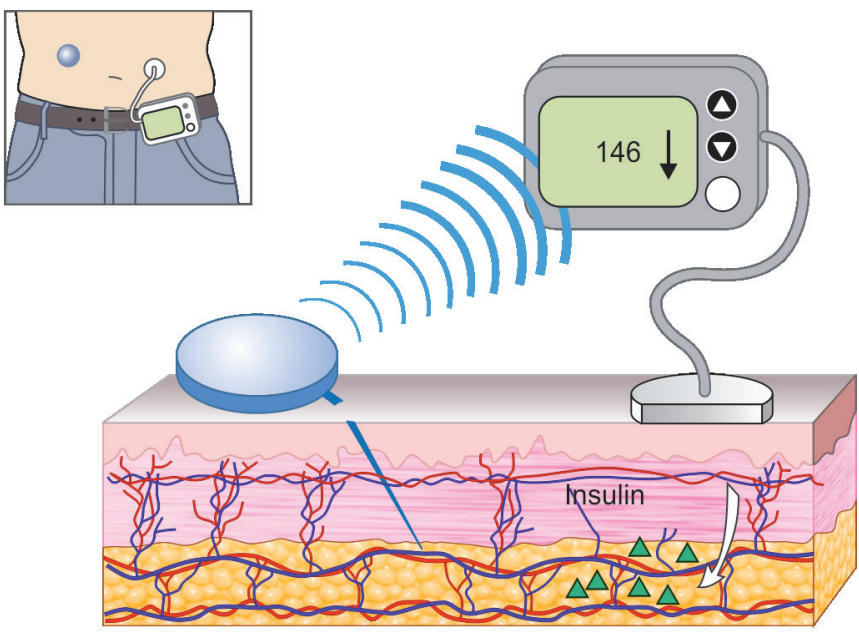

comparing a capillary fingerstick samples because of the time lag between the blood capillary and interstitial readings. ${ }^{16,17}$

- Sensors need to be replaced frequently.

- The sensors through an incision must be inserted into the skin.

- Sometimes, recalibrations with fingerprick glucose test samples are still required. ${ }^{17-19}$

\section{Conclusion}

Many accessible proof supports the protection of the device for persons with type I diabetes who are 14 years of age and older. Several other studies are in progress, including a study of children and a larger randomized controlled trial. ${ }^{20}$ The UK authors of the recent, briefs on synthetic (artificial) pancreas technologies renowned that prevalent adoption will relay on more evidence that these systems serves the expected safety and will be effective in real-life settings for a longer periods of time, and they are user-friendly and cost effective for every people to use.

\section{References}

1. Sarwar N, Gao P, Seshasai SR, Gobin R, Kaptoge S, Di Angelantonio E, et al. Diabetes mellitus, fasting blood glucose concentration, and risk of vascular disease: a collaborative meta-analysis of 102 prospective studies. Lancet 2010;375(9733):2215-2222. DOI: 10.1016/S01406736(10)60484-9.

2. Bourne RR, Stevens GA, White RA, Smith JL, Flaxman SR, Price $H$, et al. Causes of vision loss worldwide, 1990-2010: a systematic analysis. Lancet Glob Health 2013;1(6):e339-e349. DOI: 10.1016/ S2214-109X(13)70113-X.

3. Trevitt S, Simpson S, Wood A. Artificial pancreas device systems for the closed-loop control of type 1 diabetes: what systems are in development? J Diabetes Sci Technol 2016 May;10(3):714-723. DOI: 10.1177/1932296815617968.

4. United States Renal Data System. National Institutes of Health, National Institute of Diabetes and Digestive and Kidney Diseases, Bethesda, MD, 2014:188-210.

5. Hanazaki K, Munekage M, Kitagawa H, Yatabe T, Munekage E, Shiga M, et al. Current topics in glycemic control by wearable artificial pancreas or bedside artificial pancreas with closed-loop system. J Artif Organs 2016 Sep;19(3):209-218. DOI: 10.1007/s10047-016-0904-y.

6. Minimed 670G: a hybrid closed-loop insulin delivery system. Med Lett Drugs Ther 2016;58(1508):147-148.

7. lacovacci V, Ricotti L, Menciassi A, Dario P. The bioartificial pancreas (BAP): biological, chemical and engineering challenges. Biochem Pharmacol 2016;100:12-27. DOI: 10.1016/j.bcp.2015.08.107. 
8. Haidar A, Smaoui MR, Legault L, Rabasa-Lhoret R. The role of glucagon in the artificial pancreas. Lancet Diabetes Endocrinol 2016;4(6):476-479. DOI: 10.1016/S2213-8587(16) 30006-7.

9. The pharmacology in type 1 diabetes: executive summary. Available from: http://www.canadianjournalofdiabetes.com/article/S14992671(13)00061-0/pdf, 2013. pp. S310-S311.

10. Silver Spring (MD): U.S. Food and Drug Administration; 2016. Mini Med 670G system.

11. Ly TT, Weinzimer SA, Maahs DM, Sherr JL, Roy A, Grosman B, et al. Automated hybrid closed-loop control with a proportional-integralderivative based system in adolescents and adults with type 1 diabetes: individualizing settings for optimal performance. Pediatr Diabetes. 2016 May 18; Epub ahead of print.

12. Kropff J, Devries JH. Continuous Glucose Monitoring, Future Products, and Update on Worldwide Artificial Pancreas Projects. Diabetes Technol Ther 2016 Feb;18(Supp 2):S253-S263. DOI: 10.1089/dia. 2015.0345.

13. Oron T, Farfel A, Muller I, Miller S, Atlas E, Nimri R, et al. A remote monitoring system for artificial pancreas support is safe, reliable, and user-friendly. Diabetes Technol Ther 2016;18(Suppl 1): S93-S94.
14. ThabitH,Tauschmann M,Allen JM, LeelarathnaL,HartnellS, WilinskaME, et al. Home Use of an Artificial Beta Cell in Type 1 Diabetes. 2015 Nov 26;2129-2140.

15. Fradkin JE, Wallace JA, Akolkar B, Rodgers GP. Type 1 DiabetesReaping the Rewards of a Targeted Research Investment. Diabetes 2016 Feb;65(2):307-313. DOI: 10.2337/db15-1030.

16. Bell K. Medtronic's MiniMed $670 \mathrm{G}$ system approved by FDA for type 1 diabetes [Internet] FirstWord Medtech. Sep 28, 2016.

17. Malek R, Davis SN. Novel Methods of Insulin Replacement: The Artificial Pancreas and Encapsulated Islets. Rev Recent Clin Trials 2016;11(2):106-123.

18. Garg SK, Weinzimer SA, Tamborlane WV, Buckingham BA, Bode BW, Bailey TS, et al. Glucose Outcomes with the In-Home Use of a Hybrid Closed-Loop Insulin Delivery System in Adolescents and Adults with Type 1 Diabetes. Diabetes Technol Ther 2017 Mar;19(3):155-163. DOI: 10.1089/dia.2016.0421.

19. Chatterjee S, Davies MJ. Current management of diabetes mellitus and future directions in care. Postgrad Med J 2015 Nov;91(1081): 612-621. DOI: 10.1136/postgradmedj-2014-133200.

20. Rodbard D. Continuous glucose monitoring: a review of successes, challenges, and opportunities. Diabetes Technol Ther 2016 Feb;18(Suppl 2):S3-S13. DOI: 10.1089/dia.2015.0417. 